\title{
Supporting Information: \\ Reaction Mechanism of the Mandelate Anion Racemization Catalyzed by Mandelate Racemase Enzyme: A QM/MM-Molecular Dynamics Free Energy study
}

\author{
Xavier Prat-Resina ${ }^{1 \dagger}$, Àngels González-Lafont ${ }^{1,2}$ and José M. Lluch ${ }^{* 1,2}$ \\ ${ }^{1}$ Departament de Química, \\ Universitat Autònoma de Barcelona, \\ 08193 Bellaterra (Barcelona), Spain. \\ ${ }^{2}$ Institut de Biotecnologia i de Biomedicina, Universitat \\ Autònoma de Barcelona, \\ 08193 Bellaterra (Barcelona), Spain.
}

In the present supporting information we provide the plots showing the evolution of the Mulliken net charges and bond orders in the enzyme when compared to an uncatalyzed reaction. The atom labels for the substrate are shown in scheme 3 in the article.

\section{Mulliken net charges}

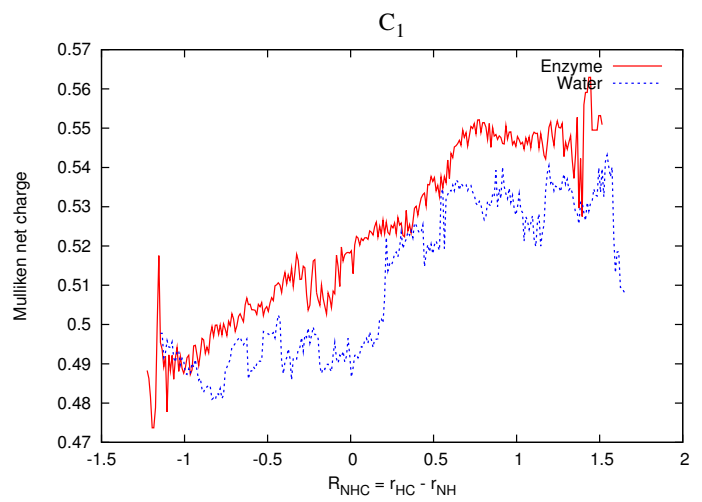

Figure 1:

${ }^{*}$ Correspondence to José M. Lluch, Departament de Química, Universitat Autònoma de Barcelona, 08193 Bellaterra (Barcelona) Spain. ${ }^{\dagger}$ Present address: Department of Chemistry and Theoretical Chemistry Institute, University of Wisconsin, Madison, 1101 University Ave, Madison, Wisconsin 53706 


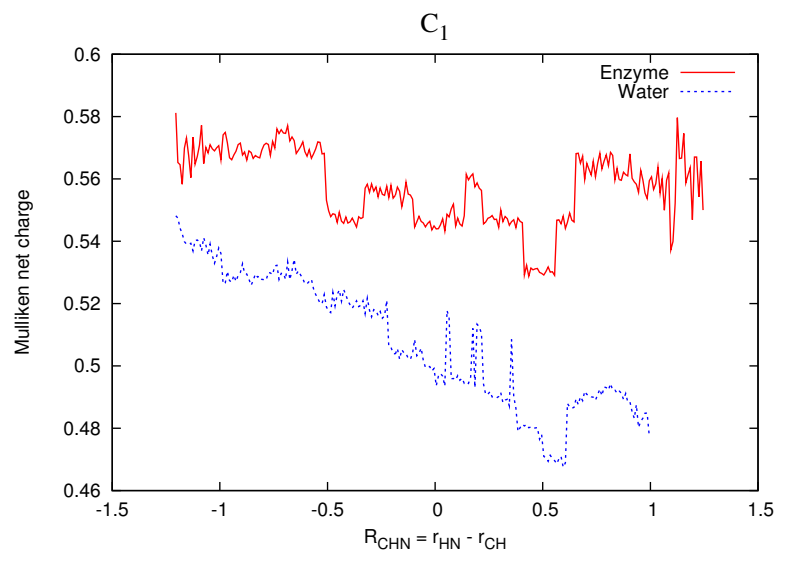

Figure 2:

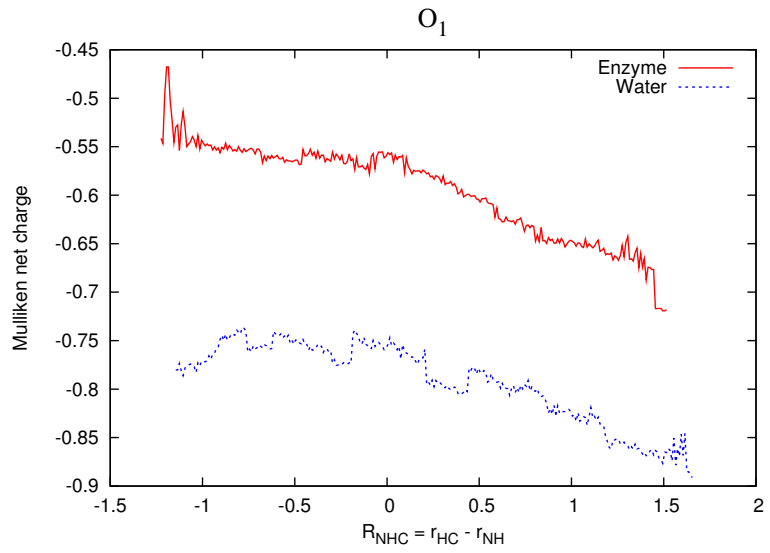

Figure 3:

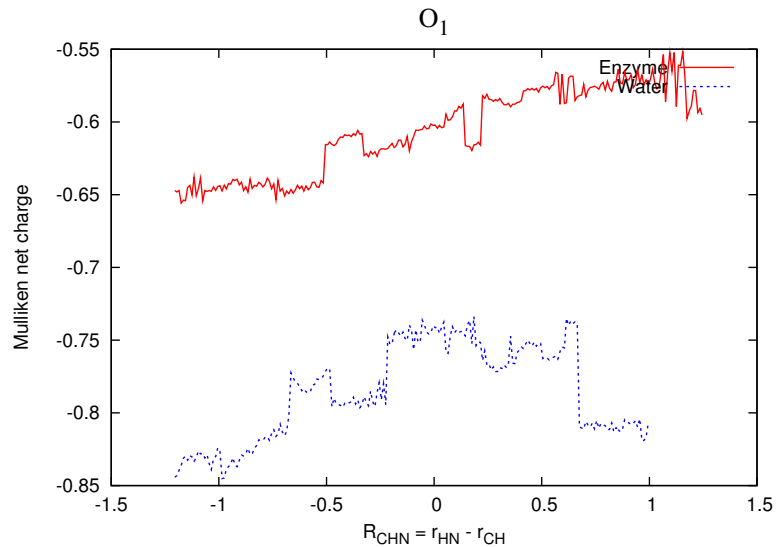

Figure 4: 


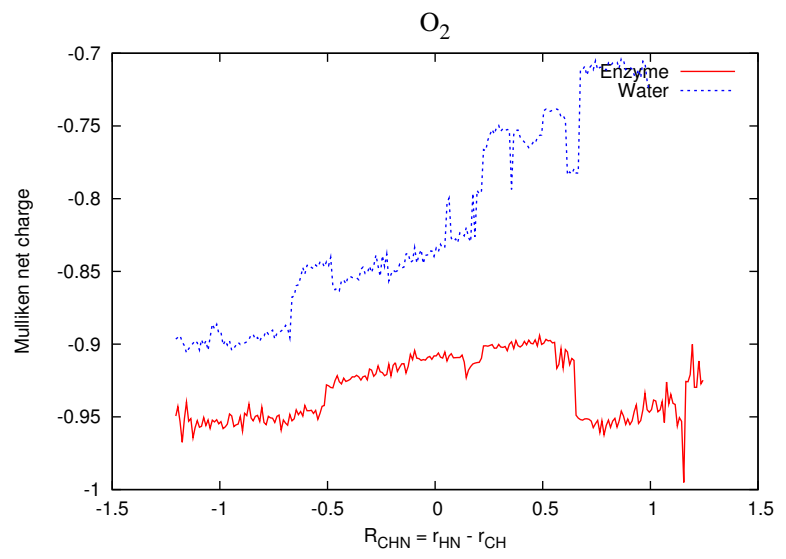

Figure 5:

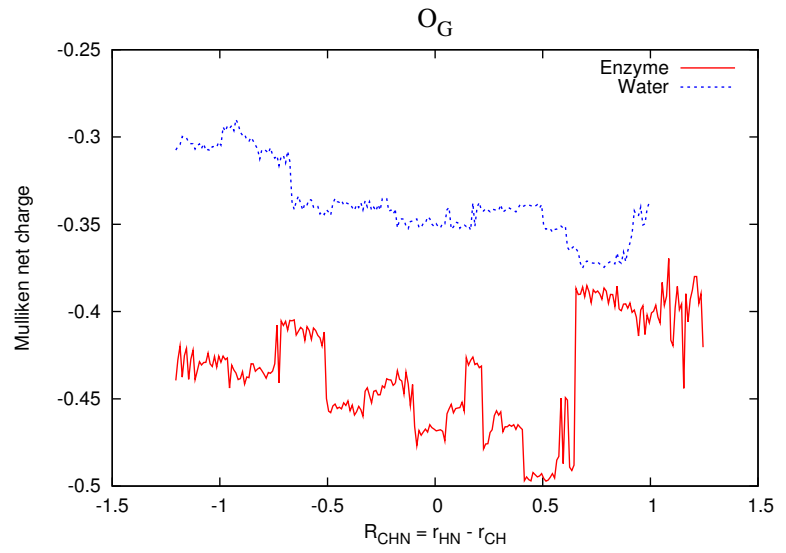

Figure 6:

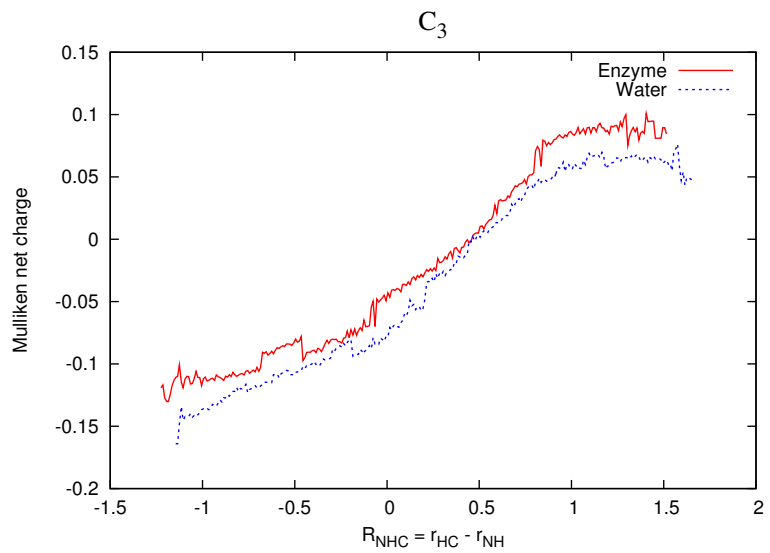

Figure 7: 


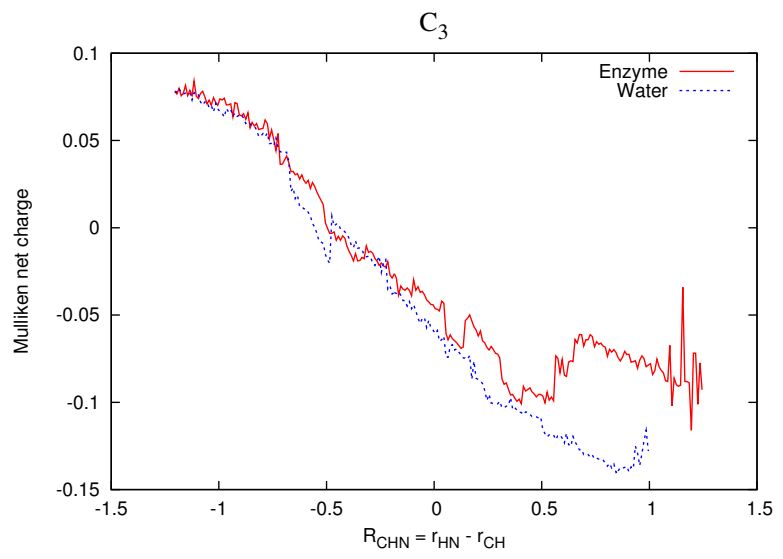

Figure 8:

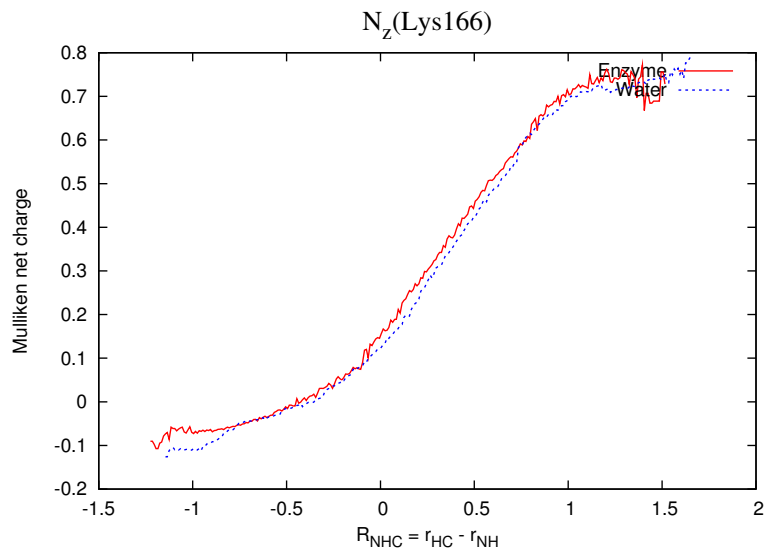

Figure 9:

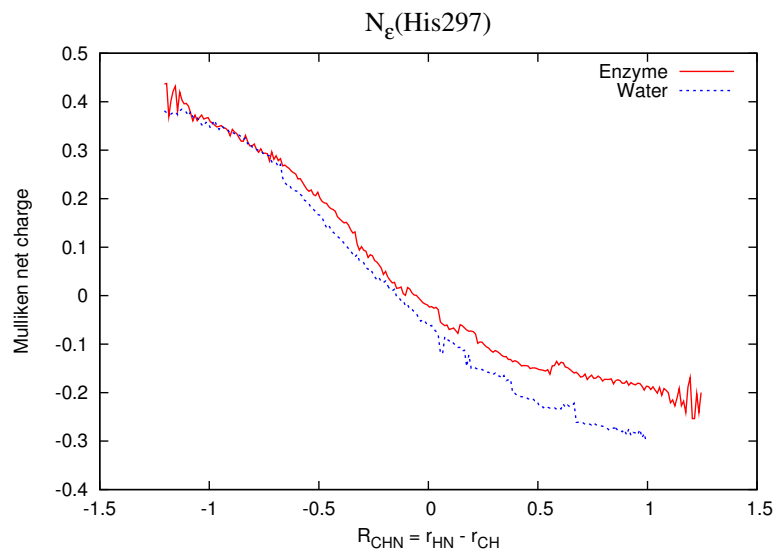

Figure 10: 


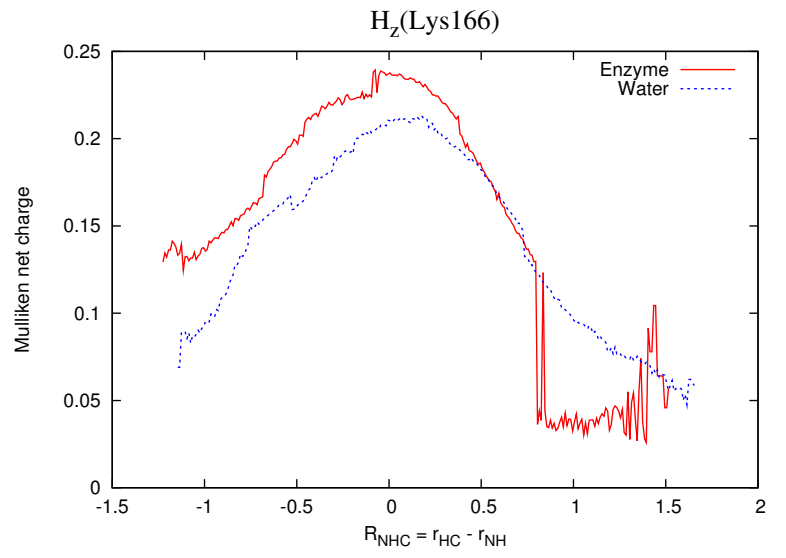

Figure 11:

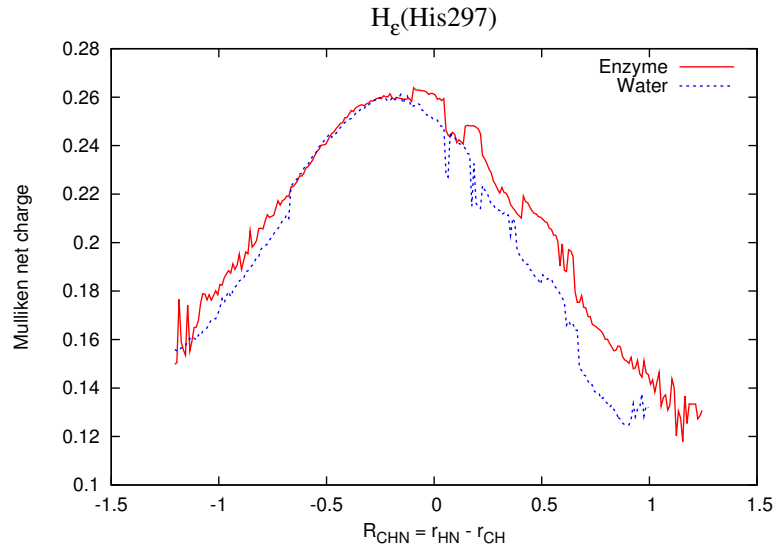

Figure 12: 


\section{Bond Orders}

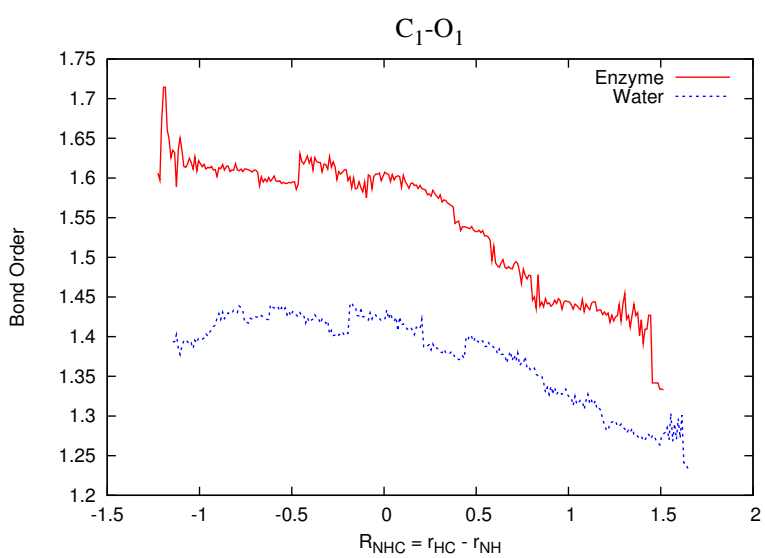

Figure 13:

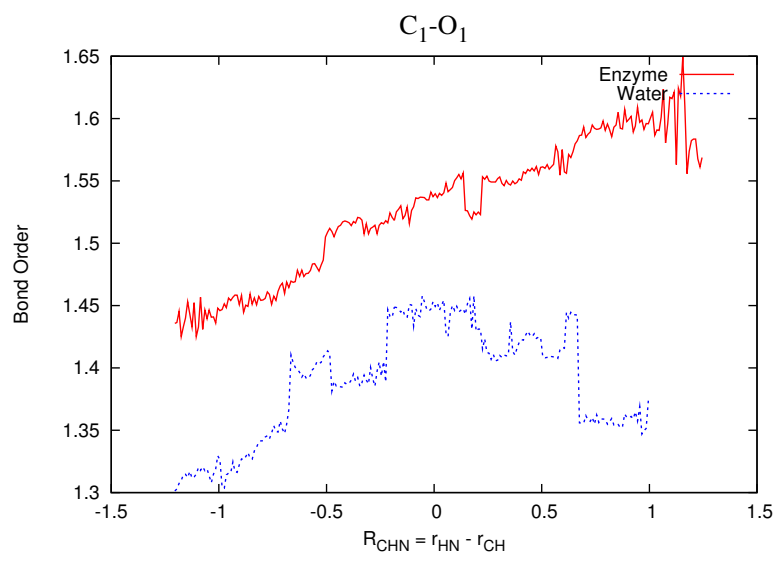

Figure 14: 


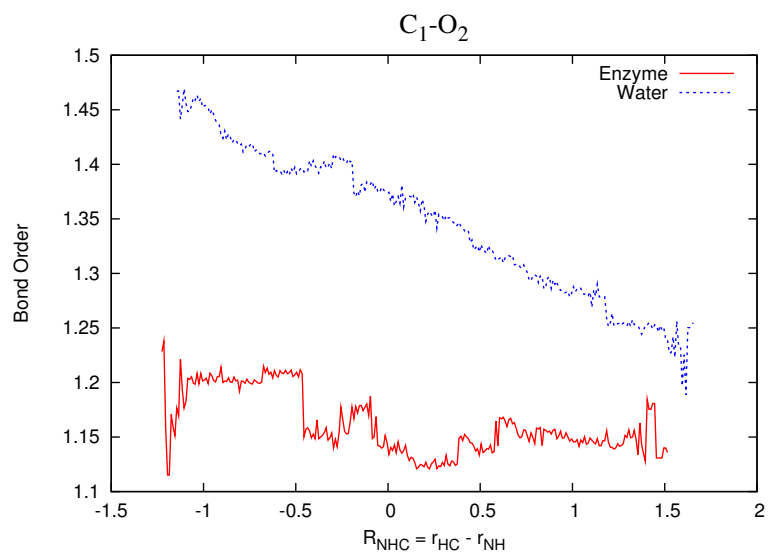

Figure 15:

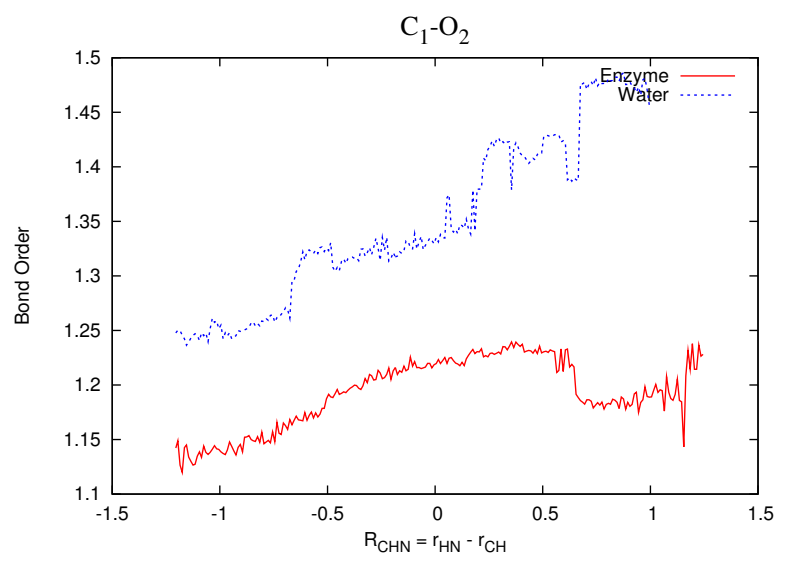

Figure 16:

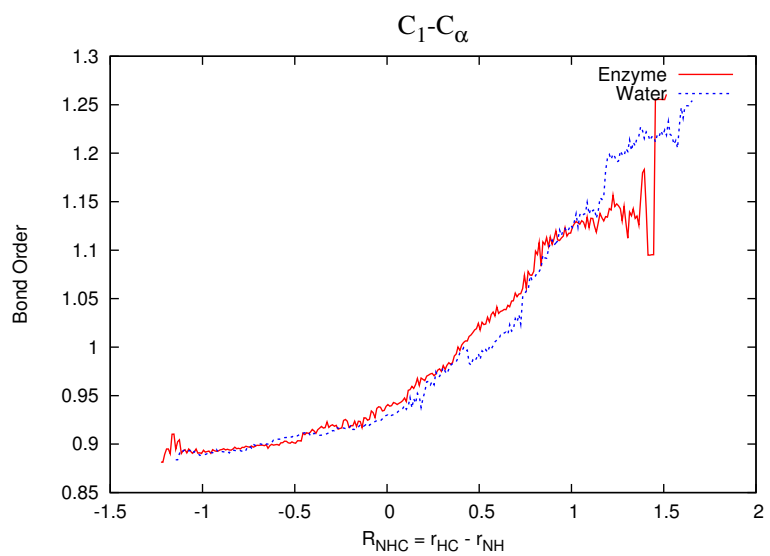

Figure 17: 


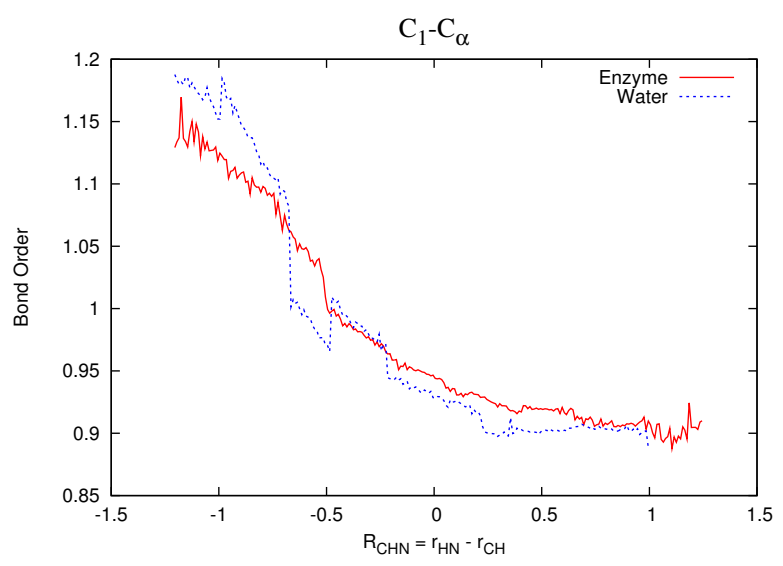

Figure 18:

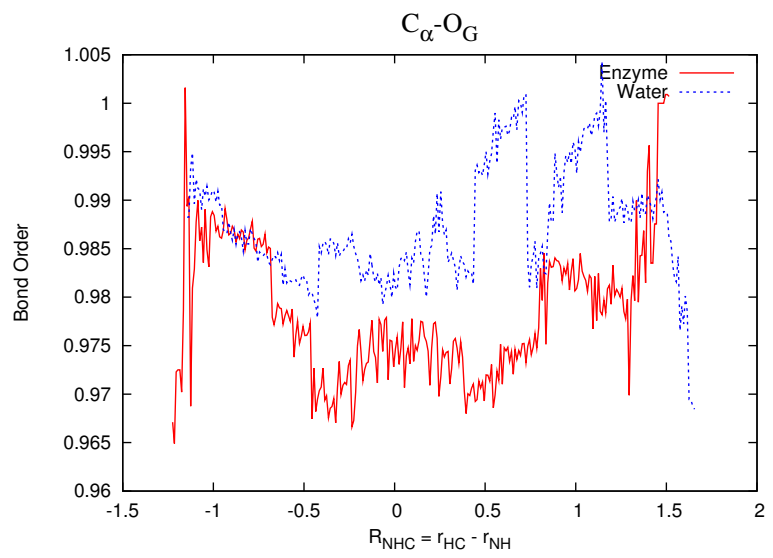

Figure 19:

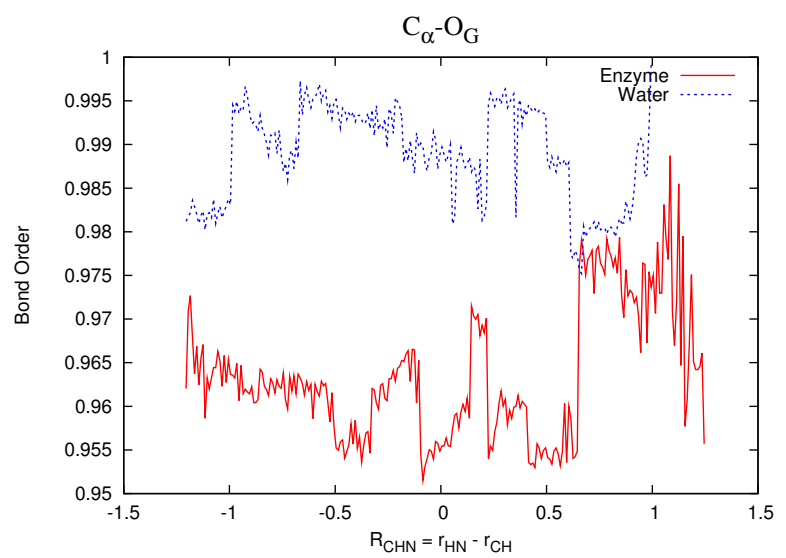

Figure 20: 


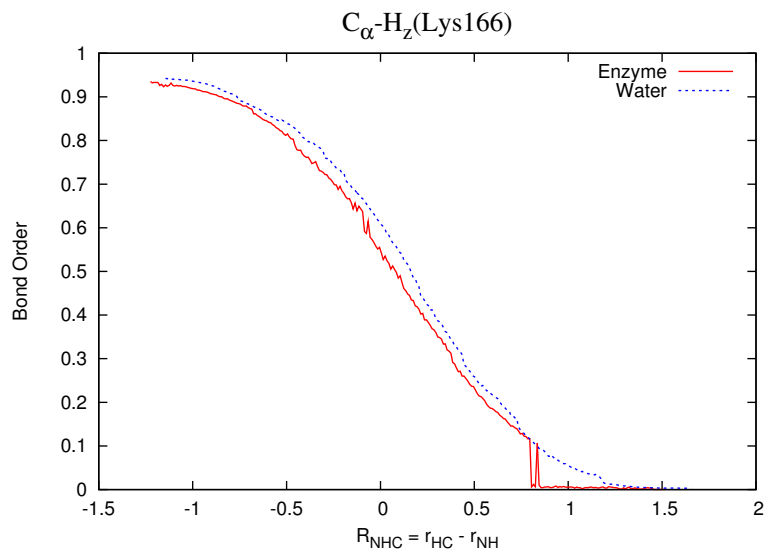

Figure 21:

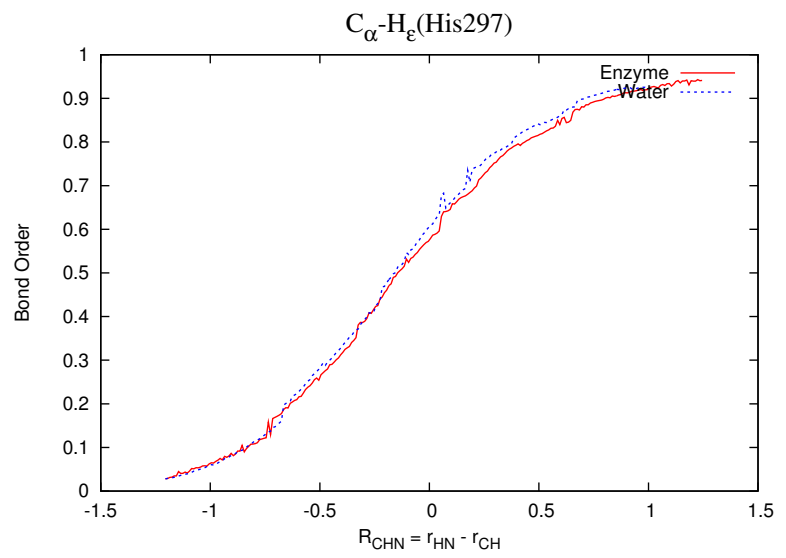

Figure 22:

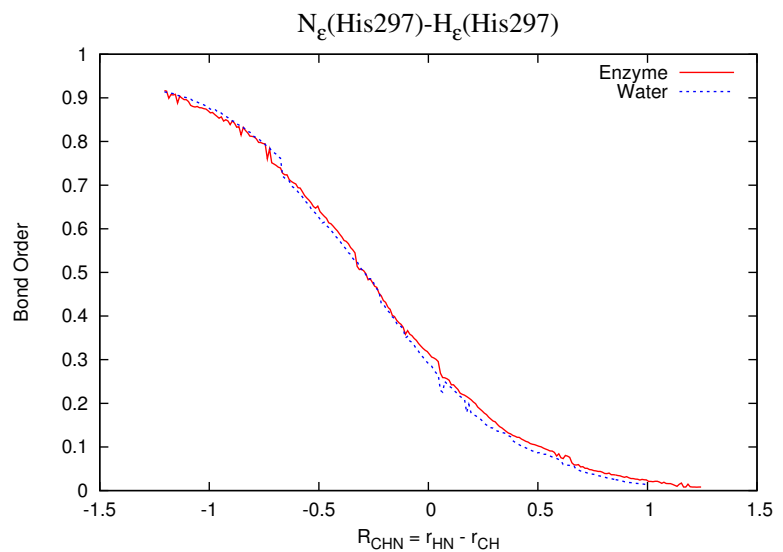

Figure 23: 